\title{
Gestão da Diversidade, Identidade e Racialização: Duas Gerações de Profissionais Negros(as) no Mundo Empresarial
}

Hasani Elioterio dos Santos'

\section{Resenha do Livro:}

JAIME, Pedro. Executivos Negros: Racismo e Diversidade no Mundo Empresarial. São Paulo: Edusp: Fapesp, 2016.

Ao nos depararmos com o texto de Pedro Jaime, encontramos um trabalho polifônico, que adotou a estratégia etnográfica de coletar narrativas de diversos sujeitos, imersos no mundo empresarial, associada a um exercício intelectual e teórico que faz uma síntese de grandes questões que dominam o campo das relações raciais e das ciências sociais.

O debate proposto por Jaime em "Executivos Negros" atualiza uma das questões mais clássicas do campo das relações raciais no Brasil, que é a inclusão e a integração do negro na sociedade brasileira. A novidade é que Jaime traz o debate por horizontes e vias ainda pouco exploradas: o campo empresarial e executivo.

O livro é desdobramento da tese de doutorado de Jaime, que foi realizada na USP, sob a orientação do professor Kabenguele Munanga, que também assina o prefácio do livro. Logo no prefácio, Munanga aponta para o objeto da discussão do livro de Jaime, "trata-se da questão racial no mundo empresarial brasileiro a partir da experiência da cidade de São Paulo, "capital" econômica do país" (Jaime 2016: 11).

1 Programa de pós-Graduação em Sociologia da Universidade Federal de São Carlos (PPGS / UFSCar) São Carlos - Brasil - hasanisantos@gmail.com. 
Para Jaime, a construção do pertencimento identitário dos executivos negros não pode ser analisada empiricamente de maneira isolada e separada das mudanças sociais que ocorreram nas últimas décadas no Brasil, e no mundo de maneira geral. Muito pelo contrário, a tese defendida no livro é a de que a construção identitária dos(as) executivos(as) negros(as) reflete as transformações e avanços no discurso do movimento negro, assim como os debates públicos em torno da questão racial na sociedade brasileira e mundial.

A primeira parte do livro consiste em uma seção expositiva em que Jaime apresenta ao leitor as categorias, conceitos e as afiliações teóricas mobilizadas por ele para a formulação do seu modelo interpretativo sobre o objeto de discussão central do livro: a questão racial no mundo empresarial.

Uma ideia central para o modelo interpretativo e para a forma de Jaime colher os dados da pesquisa é a ideia de trajetória, especificamente a trajetória profissional. Com essa ideia, Jaime observa uma autonomia dos indivíduos dentro das estruturas organizacionais. Para Jaime, Crozier e Friedberg (1992) ao trabalharem com a noção de trajetória "reconhecem que esta autonomia é relativa, contudo insistem que é possível contornar situações adversas [...] Este postulado se liga ao conceito de estratégia dos atores" (Jaime, 2016: 61).

Outro conceito que Jaime faz questão de apresentar ao leitor é o conceito de contexto societal, que segundo ele vem "[...] para fazer referência ao quadro amplo da sociedade", de tal sorte que a noção de contexto societal serve para pensar a sociedade e as dinâmicas específicas de cada sociedade. Ao trabalhar nesta chave, Jaime se apoia nas convicções de François Dubet (2009), que faz questão de superar a noção de sociedade integrada e estabilizada (ou estável), mas não a noção de Estado-Nação e suas formações sociais específicas.

O livro de Jaime também nos convida para a discussão a respeito da Produção da Sociedade, noção que Jaime extrai de Alain Touraine (1973) para pensar que a sociedade não se explica por nenhum princípio de ordem transcendente; na realidade, a sociedade tem a capacidade de se autoproduzir, e essa autoprodução se realiza graças às interações dos atores sociais e suas ações cotidianas, de tal sorte que para Touraine (1973) o conflito é central para pensar a produção da sociedade. Nesse sentido, há uma potência analítica de se ver a capacidade dos movimentos sociais e das lutas sociais ${ }^{2}$ de produzir e construir a sociedade por meio do conflito e das ações coletivas.

2 Touraine (1973) faz uma diferenciação entre movimentos sociais e as lutas sociais, as lutas modificam as tomadas de decisões políticas e os movimentos seriam os responsáveis pelas ações coletivas que mobilizam o conflito e sua capacidade de produzir sociedade. 
Outra noção trabalhada por Jaime em seu livro é o espaço público para dialogar com Habermas (2003) e Fraser (2005) a respeito do lugar onde ocorrem as discussões e tomadas de decisões políticas na sociedade. Assim, as mudanças que ocorreram na sociedade civil com base nas mobilizações do movimento negro, como a promulgação do Estatuto da Igualdade Racial e as políticas de ações afirmativas, por exemplo, refletem para Jaime a influência dos movimentos sociais nas tomadas de decisão na esfera pública.

No livro, a articulação entre as concepções de espaço público e de globalização lança luz a uma nova forma de administração da circulação e do fluxo de capitais, pessoas, informações e ideias a um nível global que transcende o espaço local. Para Jaime, os anos de 1990 são centrais para a intensificação desse fluxo graças ao desenvolvimento das tecnologias da informação. Ao articular as noções de espaço público e globalização, Jaime pensa em uma rede transnacional de pautas que passam a ser adotadas pelos movimentos sociais de maneira global e local; é o caso do advocacy antirracista que, para o autor, é o que leva as empresas a trabalharem com a questão da diversidade.

A última discussão conceitual importante para a construção do seu modelo interpretativo de como se opera a questão racial no ambiente empresarial e corporativo são as noções de sujeito e identidade. A noção de sujeito que Jaime utiliza tenta pensar em como os sujeitos são transpassados pelas suas experiências e se tornam agentes, principalmente quando estes mobilizam a noção de identidade. A identidade nesse caso se aproxima muito mais do que os sujeitos pretendem ser, querem ser e se tornar, do que com o que eles são ou de onde vieram. Desse modo, Jaime analisa o mundo empresarial e sua relação com a questão racial de uma maneira que os fenômenos sociológicos que lhe interessam são, na realidade, as ações e estratégias de sobrevivência e resistência dos executivos negros no mundo dos negócios.

$\mathrm{O}$ autor, portanto, faz uma brilhante discussão teórica a respeito das noções de contexto societal, trajetória profissional e construção do sujeito para poder comparar duas gerações diferentes de executivos(as) negros(as). Ele recorre a um dos exercícios mais clássicos das ciências sociais, que é o método comparativo, e compara o que ele caracteriza como a primeira geração de executivo(as) negros(as), aquela que ingressou no mercado de trabalho no fim dos anos 1970, com a segunda geração, a que ingressou no início do Século XXI. A diferença entre as duas gerações é determinada pela agenda política do movimento e das organizações negras.

A principal discussão presente no livro, e que considero como o eixo analítico central para a comparação das duas gerações de executivos negros, é a forma e o 
modelo de organização política dos movimentos negros. No início dos anos 1930 havia uma forte presença das lutas e mobilizações da Frente Negra Brasileira que perdurou até o fim da década de 1970, com a formulação do Movimento Negro Unificado, que por sua vez incorporou pautas políticas de viés trotskista em que havia uma crítica ao modelo capitalista de estruturação da sociedade e esse enquadramento capitalista não contribuía com a vida da maioria da população negra no Brasil. É esse momento que marca a primeira geração de executivos negros e todo o debate sobre a questão racial e a recepção do tema pela sociedade brasileira.

Jaime faz uma excelente síntese histórica do movimento negro dentro do processo de produção de sociedade brasileira. $\mathrm{O}$ autor coloca de maneira analítica uma centralidade nas lutas antirracistas no Brasil e no protagonismo das organizações e movimentos negros a partir do contexto pós-abolição até o início do Século XXI, de modo que há para ele quatro marcos históricos fundamentais para a análise, que são:

a) a emergência de uma imprensa negra nos anos 1920, que resultou na formação da Frente Negra Brasileira (FNB) em 1931; b) a criação do Teatro Experimental do Negro (TEN), em 1944; c)a fundação do Movimento Negro Unificado (MNU), em 1978; d) o surgimento de diversas ONG's oriundas do movimento negro a partir do final dos anos 1980 e início dos anos 1990." (Jaime, 2016: 106)

Nesse sentido, a luta antirracista dos anos 1920 fica marcada pelos jornais da imprensa negra, como O Clarim da Alvorada, por exemplo, jornal que era responsável pelo incentivo à escolarização da população negra. Nesse contexto, a Frente Negra Brasileira (FNB) e o slogan "elevação da raça" chamava atenção para o debate da inserção do negro no espaço público e em postos de destaque na sociedade brasileira. Outro periódico, intitulado A Voz da Raça era um material de divulgação das iniciativas da FNB que viveu ativamente até o golpe que instituiu o Estado Novo e até o momento em que Getúlio Vargas decreta o fechamento de todos os partidos políticos.

Já nos anos 1970 há um momento em que a sociedade civil está mobilizada e unida em volta da reconquista da reabertura democrática. É nesse momento que diversas entidades vinculadas aos direitos da população negra se reúnem e se organizam em uma frente ampla de combate ao racismo. Interessante no livro é que esse momento é analisado por Jaime levando em consideração o contexto internacional das lutas por direitos civis e por reconhecimento nos Estados Unidos, assim como as lutas de descolonização no continente africano, de tal sorte que esses eventos internacionais serviram de fontes de potência para a criação do Movimento Negro Unificado (MNU) no Brasil. 
Diversas conquistas e alterações nas dinâmicas sociais foram alcançadas pelas lutas antirracistas como o combate ao racismo no campo econômico. No plano político-institucional, o MNU esteve à frente de uma campanha para propor o nome de Zumbi dos Palmares como figura simbólica da liberdade negra no Brasil, em contraponto com a figura da Princesa Isabel, que foi falsamente forjada. Desse modo, a data de 20 de Novembro foi proposta pelo MNU como o Dia da Consciência Negra, em oposição ao dia 13 de maio, que é a data oficial da Abolição da Escravatura no Brasil.

No contexto de luta e protagonismo político do MNU havia uma confluência e uma articulação entre o discurso de combate às discriminações raciais e as desigualdades de classe. Isso foi algo que mudou radicalmente as experiências de lutas antirracistas que existiam anteriormente, nos anos 1930 e 1940. Jaime dá destaque para a relação do MNU com a Convergência Socialista, uma organização clandestina de viés marxista trotskista que ofereceu treinamento para diversos intelectuais do $\mathrm{MNU}^{3}$. Além disso, os anos 1970 contavam com a Guerra Fria como grande acontecimento nas dinâmicas geopolíticas que determinava o tom da polarização mundial em capitalismo/socialismo.

Já a partir dos anos 1990 houve a ocorrência do fenômeno que a literatura caracteriza como a onguização do movimento negro. Esse momento representa o modo de o movimento negro passar a adotar a forma de um grande número de organizações não governamentais. Esse fenômeno representa muito menos o enfraquecimento do movimento negro senão a adaptação do próprio movimento a um novo contexto de sociedade civil. Para Jaime, esse momento se caracteriza também pelo aumento da capacidade de interlocução (ou diálogo) com os governos e, nesse sentido, aumentou-se a possibilidade de implementação de políticas públicas.

As conclusões de sua análise sobre as duas gerações de executivos negros é uma das discussões mais interessantes que podemos encontrar ao decorrer da leitura do livro. Jaime relaciona as mudanças ocorridas na construção das trajetórias profissionais dos executivos negros em São Paulo da primeira geração e da segunda geração com as mudanças produzidas na sociedade em relação à questão racial, e como essas mudanças na sociedade favoreceram ou inibiram a construção de si dos executivos negros dentro do ambiente corporativo e empresarial.

Nesse sentido, a passagem de uma geração para a outra é caracterizada pelos marcos temporais e históricos do fim dos anos 1970 e o início do Século XXI e

3 HANCHARD, Michael George. Orfeu e o poder: o Movimento Negro no Rio de Janeiro e São Paulo (19451988). Rio de Janeiro: Eduerj, 2001. 
as formas de ação e de estratégia de combate à discriminação racial que eram possíveis para os entrevistados de Jaime. Portanto, a construção das trajetórias profissionais dos executivos negros na cidade de São Paulo é caracterizada por Jaime pela transição de estratégias individuais para uma ação coletiva.

Os indivíduos entrevistados que compõem os executivos da primeira geração narraram suas experiências no ambiente empresarial a partir do fim dos anos 1970. Segundo Jaime, o contexto societal era desfavorável a uma discussão franca e a um suporte contra as discriminações raciais dentro do ambiente de trabalho. Nesse momento, o Brasil não havia implementado de maneira efetiva políticas públicas voltadas ao combate à discriminação racial e à diminuição das desigualdades raciais. O Brasil estava sob o governo da ditadura militar e o MNU estava se formando em 1978, mesmo assim a afiliação aos princípios marxistas afastavam muitos dos que aspiravam a ter uma carreira executiva a participar do movimento negro organizado naquele momento.

Neste período, as estratégias de enfrentamento e combate às discriminações diárias desses indivíduos no espaço de trabalho foram estratégias individuais que lhes permitiram atingir os objetivos de carreira profissional e ignorar e "esquecer" os casos de racismo e discriminação. Esses executivos se blindavam e tinham condutas defensivas frente aos atos discriminatórios racistas e sexistas dentro do ambiente de trabalho; muitas vezes, eles e elas evitaram o conflito direto.

Nesse sentido, o autor argumenta que isso não significa que uma atitude defensiva significa um processo de embranquecimento ${ }^{4}$, pois esses indivíduos, ao ignorar e resolver "esquecer" o racismo, não puderam passar ilesos às discriminações. Muitos narraram a Jaime o custo emocional que a somatização do racismo com a tentativa de blindar a discriminação diária e atingir os objetivos no trabalho teve em suas vidas.

A segunda geração é forjada pela construção de políticas públicas para o enfrentamento direto com a discriminação racial na sociedade civil que ocorreu desde meados dos anos 1980. Para o autor, no fim do Século XX "houve uma maior politização dos debates sobre a questão racial travados no espaço público brasileiro" (Jaime, 2016: 395). É na transição entre o fim do Século XX e o início do Século XXI que diversas ações, que visavam combater o racismo estrutural e a discriminação racial, surgiram na sociedade brasileira. Foi nesse contexto que as universidades públicas implementaram a política de ações afirmativas para a inclusão do negro no Ensino Superior.

4 Nesse sentido, Jaime avança e faz uma interessante crítica à tese defendida por Florestan Fernandes em seu notório trabalho A integração do Negro na Sociedade de Classes sobre o negro de alma branca. Ver mais em: FERNANDES, Florestan. A Integração do Negro na Sociedade de Classes. São Paulo, Globo, 2008, 2 vols. 
O movimento negro institucionalizado na forma de ONGs pressionou não só o Estado brasileiro, mas também empresas privadas para que se responsabilizassem socialmente com a diminuição das desigualdades raciais. Jaime destaca que em 2003 houve uma representação ao Ministério Público do Trabalho de Brasília (MPT) e o MTP respondeu às cobranças das ONGs lançando o Programa de Promoção da Igualdade de Oportunidades para Todos (PPIOT). Nesse mesmo ano, alguns inquéritos civis públicos foram instaurados nos cinco maiores bancos que operavam no Brasil.

Em 2004, o MPT propôs o estabelecimento de um Termo de Ajuste de Conduta (TAC) para ajuizar ações civis públicas contra as empresas que não trabalhavam na chave das diminuições de desigualdade. No ano de 2006, a Faculdade Zumbi dos Palmares, chamada de Unipalmares na época, fez parcerias com diversos bancos para implementar programas de trainees destinados a jovens negros; em 2007, a Federação Brasileira de Bancos (Febraban) realizou um recenseamento dos funcionários para averiguar a composição racial do setor bancário.

Para Jaime, esse contexto marca a porta de entrada da segunda geração de executivos negros no mundo corporativo, favorecendo a construção positivada de suas trajetórias profissionais, de modo que a essa geração não se molda pelo conjunto de trajetórias individuais e isoladas de executivos negros, como a primeira geração, mas são trajetórias coletivas, fruto das pressões exercidas pelo movimento negro nas empresas e companhias.

Mas há uma contrapartida na conclusão de Jaime que assevera que, mesmo os bancos e as empresas privadas respondendo com certa rapidez às pressões das organizações negras, a consistência dessa resposta pode e deve ser questionada e interpelada. Para o autor, "os bancos encontraram uma metodologia administrativa que lhes permitiu traduzir essa pressão numa linguagem empresarial: a gestão da diversidade" (Jaime, 2016: 396). Nesse sentido, a gestão da diversidade é utilizada pelas empresas para gerenciar e para responder aos conflitos existentes na sociedade.

Dessa maneira, há uma conclusão crítica de Jaime em relação ao modo com que as empresas estão trabalhando com a diversidade e a questão racial no ambiente corporativo, de modo que o processo de racialização ainda ocorre no mundo corporativo. Segundo Jaime, os executivos negros da segunda geração, ao contrário da primeira, "[...] são racializados no mundo corporativo como sujeitos (eu sou um negro!) e não mais como objetos (olha lá um negro!). Isso porque, por trás de cada um deles como sujeitos, com "s" minúsculo, há um Sujeito, com "s" maiúsculo: o movimento negro" (Jaime, 2016:397). 


\section{Referências}

DUBET, François. Le travail des sociétés. Paris, Seuil, 2009.

FRASER, Nancy. Qu'est-ce que la justice sociale? Reconnaissance et Redistribuition. Paris, La Découverte, 2005.

HABERMAS, Jurgen. O Papel da Sociedade Civil e da Esfera Publica Política. In:

Direito e Democracia. Rio de Janeiro, Tempo Brasileiro, v. 2, 2003.

JAIME, Pedro. Executivos Negros: Racismo e Diversidade no Mundo Empresarial. São Paulo, Edusp, Fapesp, 2016.

TOURRAINE, Alain. Production de La societé. Paris, Seuil, 1973 (542).

Recebido em: 01/04/2019

Aprovado em: 12/05/2019

\section{Como citar esta resenha:}

SANTOS, Hasani Elioterio dos. Gestão da Diversidade, Identidade e Racialização: Duas Gerações de Profissionais Negros(as) no Mundo Empresarial. Contemporânea Revista de Sociologia da UFSCar, v. 9, n. 2, maio - agosto. 2019, pp. 693-700. 